\title{
Assessing the Influence of Aggregates and Cement Types on Fresh Roller Compacted Concrete Mixture
}

\author{
Saad I. Sarsam 1, *
}

${ }^{1}$ Professor, Sarsam and Associates Consult Bureau (SACB), Baghdad-IRAQ. Formerly at Department of Civil Engineering, College of Engineering, University of Baghdad, Iraq

${ }^{*}$ Corresponding author email: saadisasarsam@coeng.uobaghdad.edu.iq

DOI: https://doi.org/10.34256/irjmt2134

Received: 23-03-2021, Revised: 26-04-2021, Accepted: 03-05-2021, Published: 04-05-2021

Abstract: Roller compacted concrete mixture RCC is considered as a sustainable pavement construction material, it is a heavy-duty concrete mixture with zero slump. An attempt has been made in the present investigation to design the fresh RCC mixture using two types of coarse aggregates (crushed and rounded), two types of fine aggregates (silica and river sand) and two types of cement (ordinary Portland and sulphate resistance). Concrete mixtures with dense gradation were prepared and compacted according to modified proctor design procedure. A moisture-density test was used to determine the maximum density and optimum moisture content and of RCC mixtures for each mix. Five different percentages of cement $(10-18) \%$ are implemented and six different percentages of moisture $(4-8) \%) \%$ are used to determine the dry density-moisture content relationships. It was observed that the maximum dry density of rounded aggregates mixture is higher than that of crushed aggregate mixture by $(4.2,8.3,4.2,4.2$, and 5.1$) \%$ and $(4.1,1.4,4.1,2.0$, and 2.7$) \%$ for $(18,16,14,12$, and 10$) \%$ cement content respectively for mixtures constructed with silica and river sands respectively with ordinary Portland cement. However, the maximum dry density of rounded aggregate mixture is higher than that of crushed aggregate mixture by $(3.5,4,7.1,5.5$, and 4.4$) \%$ and $(2.7,4.8,2.3,4.4$, and 4.2$) \%$ for $(18,16,14,12$, and 10$) \%$ cement content respectively for mixtures constructed with silica and river sands respectively with sulphate resistance cement. It was concluded that $12 \%$ of Portland cement and (6 to 7 ) \% of moisture are proper combination when silica or river sand were implemented, while (12 and 14) \% of sulphate resistance cement and (6 to 7) \% of moisture are proper combination when silica or river sand were implemented. abstract must be a precise and reflection of what is in your article.

Keywords: Density, Roller Compacted Concrete, Compaction, Crushed aggregate, Silica Sand.

\section{Introduction}

In the mixture design of roller compacted concrete, the ability to compact the concrete is one of the important factors to achieve high strength. However, workability of the mixture is a major factor to provide workable material. Satisfying both properties is not an easy issue to achieve because of the influence of various factors such as aggregate type and gradation, cement type, and water content. Proper combination of materials ingredients is considered as significant issue for providing adequate workability for compaction of the concrete mixture. [1] investigated 21 mixes of roller-compacted concrete (RCC). Six different water contents and four aggregate gradations were assessed using modified proctor compaction and dry density. It was revealed that the range of proper water content for acceptable workability is narrower than that of appropriate water content corresponding to the acceptable dry density. It was concluded that it is more difficult to get proper workability than getting acceptable dry density. [2] stated that in RCC, the amount of cement is usually considered between (100 and 200) $\mathrm{kg} / \mathrm{m}^{3}$, while the water content ranges from (100 to 150) $\mathrm{kg} / \mathrm{m}^{3}$ and the air content is around $(1-3) \%$.

Hamzah and Al-Shadeedi, [3] investigated the analytical behavior of various mixes of roller compacted concrete RCC using different materials. It was revealed that using crushed coarse aggregate increases the interlocking process between particles of aggregate and provides better mechanical properties than the case with uncrushed aggregate. It was concluded that crushed aggregate needs more water to cement ratio and the magnitude of density of RCC decreases when using crushed aggregate, since the rounded particles 
decrease the voids. Kwan and Chen, [4] shows in their work how the variation in different mineral additives content led to the change in water demand and packing density of the concrete mixture. It was stated that with the increment in the fine materials content, the packing increased up to a certain optimum limit of these materials and the further increment in the fines content had lowered the density values. The possible reason for such behavior may be that the higher fine content leads to increase in the specific surface area and the water demand and lowers the packing density.

Pathania et al., [5] addressed that the concept of particle packing is very important factor in production of concrete with good properties such as durability and strength. Implementation of mineral additives with lower particle size than that of cement, can improve the packing process by taking up the voids between the cement grains and reducing the water demand. The appropriate measure for the particle packing process involves the selection of appropriate sizes of aggregates material so that to get minimum voids and maximum packing density. [6] investigated a wide range of RCC aggregate gradations. It was observed that the modified proctor compaction method has yielded a relatively narrow range of maximum dry densities (mostly between 2,330 and 2,400 kg/m 3 ) and optimum moisture contents (mostly between 6.2 and $6.7 \%$ ) for all gradations implemented. It was noted that the coarse-fine aggregate ratio was the major parameter to be linked directly to RCC compressive strength. Aggregate's type such as gravel and siliceous rounded sand, and crushed aggregates was also shown to influence the aggregate packing density and RCC properties.

Moradi and Shahnoori, [7] stated that replacing of fine aggregates with dredged marine sediment, improved the particle packing density of a cementitious system of roller compacted concrete, this was related to the blockage of continuous capillary pores caused by these particles. Such replacement of raw sand maintained or decreased the available pores, sorptivity, and water penetration depth under pressure. [8] stated that rounded aggregates perform better than crushed aggregates in concrete mixture because the rounded shape aggregates can improve the workability and reduce the need of mixing water. It was concluded that uncrushed aggregates are more suitable for medium grade concrete mixture for its better performance in terms of workability, economy, and strength. [9] assessed the possibility of optimization of RCC mixture depending on a proper selection of aggregates combination for achieving optimum particles size distribution and high packing density.
It was observed that the compressive strength of the optimized RCC mixtures was almost equal to that of conventional concrete, while flexural strength increased by $20 \%$ to $25 \%$ as compared to the conventional concrete. [10] presented a stepwise mixture design methodology for aggregate proportioning and particle-size distribution of combined aggregates which may secure high packing density and lead to enhanced performance of RCC mixture. [11], assessed the influence of aggregate gradation, curing conditions, cement dosage, water content, and chemical additives on RCC characteristics. It also indicated that $98 \%$ compaction degree with respect to modified proctor compaction, could be reached to attain higher compressive strength values. [12] revealed that there are several methods for mixture proportioning process to produce RCC. The maximum dry density method is one of the most widely used mixture proportioning techniques for RCC pavements. This method consists of the choice of well-graded aggregates, selection a proper cement content, preparation a moisture-density relationship plots based on the Proctor test, and casting samples for measuring the compressive strength and calculating mixture proportions. [13] reported that RCC fresh and hardened properties are considerably influenced by the mixing water.

The maximum dry density method, which means having optimum moisture content at maximum dry density, is generally implemented for the mix proportioning of RCC. The engineering properties of RCC at different moisture contents of $(4.5,5,5.5,6$, 6.5 , and 7$) \%$ and $12 \%$ cement were investigated. Test results revealed that $\mathrm{RCC}$ at $5.7 \%$ moisture content had the maximum dry density, while best mechanical performance, lowest water absorption and porosity values were obtained at $5 \%$ moisture content. It was addressed that a workable, high strength, and durable RCC can be made with a moisture content less than the optimum moisture content, which is corresponding to the maximum dry density. [14] reported that the quality of the aggregates has a significant impact on the properties of RCC concrete and it should be optimized.

The study assessed the impact of coarse to fine aggregate ratio on the fresh and hardened properties of RCC with cement contents of (9 and12) $\%$. It was concluded that increasing the ratio from 0.6 to 1.2 significantly decreased the porosity of RCC, to about (60 to 38) \% for RCC with (9 and 12) \% cement. Thus, to attain a workable, high-strength and durable RCCP, a mix with $12 \%$ cement and 1.2 ratio is recommended. Fardin and Santos, [15] investigated the physical and mechanical properties of Roller 
Compacted Concrete used with recycled concrete aggregate as a partial replacement for coarse aggregate. The maximum dry density method was implemented to prepare RCC mixtures with $200 \mathrm{~kg} / \mathrm{m}^{3}$ of cement content and coarse aggregates. The compaction test, water absorption, porosity, and density tests were performed to analyze the physical and mechanical properties of the mixtures. Calis and Yıldizel, [16] reported that in pavements, the less cost of RCC, high compressive strength, easiness to open to the traffic, and longer service life are the main reasons for RCC to be preferred.

The aim of the present investigation is to design the fresh RCC mixture using two types of coarse aggregates (crushed and rounded), two types of fine aggregates (silica and river sand) and two types of cement (ordinary Portland and sulphate resistance). The variation in the dry density among the abovementioned variables will be analyzed and discussed.

\section{Materials and Methods}

\subsection{Cement}

Sulfate resistant and ordinary Portland cement manufactured in Iraq with a commercial name of (Aljesser and Tasluga,) respectively are implemented for $\mathrm{RCC}$ mixtures throughout the present investigation. The used cement complies with the Iraqi specification IOS, No.5, [17]. The physical properties of the cement used are illustrated in Table 1. The chemical compositions of the cement are listed in Table 2.

\subsection{Fine Aggregate}

Silica sand was obtained Al-Akhaider quarry and river sand was obtained from Tozkrmato site are implemented for RCC mixtures. The fine aggregates pass sieve No. 4 are cleaned by washing on sieve No.200. fine aggregates are oven dried and stored. The chemical and physical properties of both sand types are listed in Table 3.

Table 1. Physical properties of cement

\begin{tabular}{|l|c|c|c|c|}
\hline \multirow{2}{*}{ Physical Properties } & \multicolumn{2}{|c|}{ Test Results } & \multicolumn{2}{c|}{ OS No.5, [17] Limits } \\
\cline { 2 - 5 } & OPC & SRPC & OPC & SRPC \\
\hline Specific Surface area, Blaine method, $\mathrm{m}^{2} / \mathrm{Kg}$ & 258 & 357 & $\geq 230$ & $\geq 250$ \\
\hline Setting time, Vicat Method & & & \multicolumn{2}{l}{} \\
Initial setting time, (hour : $\min$ ) & $2: 35$ & $1: 30$ & $\geq 45$ minutes \\
Final setting time, (hour : min) & $4: 45$ & $4: 10$ & $\leq 10$ hours \\
\hline Compressive strength (MPa) & & & \multicolumn{2}{|l}{} \\
3-days & 15.8 & 18.3 & $\geq 15$ \\
7-days & 20.3 & 23.8 & $\geq 23$ \\
\hline
\end{tabular}

Table 2. Chemical composition of cement

\begin{tabular}{|c|c|c|c|c|}
\hline \multirow{2}{*}{ Oxides } & \multicolumn{2}{c|}{ Percentage Content } & \multicolumn{2}{c|}{ IOS No.5, [17] limits } \\
\cline { 2 - 5 } & OPC & SRPC & OPC & SRPC \\
\hline $\mathrm{CaO}_{\mathrm{SiO}_{2}}$ & 55 & 60.63 & ----- & ----- \\
\hline $\mathrm{Fe}_{2} \mathrm{O}_{3}$ & 18.33 & 21.63 & ----- & ----- \\
\hline $\mathrm{Al}_{2} \mathrm{O}_{3}$ & 3.28 & 4.76 & ----- & ----- \\
\hline $\mathrm{MgO}_{\mathrm{SO}}$ & 5.88 & 4.19 & ----- & ----- \\
\hline $\mathrm{SO}_{3}$ on Ignition & 1.93 & 2.72 & $\leq 5$ & $\leq 5$ \\
\hline $\mathrm{I.R}$ & 1.87 & 2.04 & $\leq 2.8$ & $\leq 2.5$ \\
\hline $\mathrm{L} . S . F^{\mathrm{S}}$ & 2.36 & 1.94 & ---- & ---- \\
\hline $\mathrm{C}_{3} \mathrm{~S}$ & 0.15 & 0.92 & $\leq 1.5$ & $\leq 1.5$ \\
\hline $\mathrm{C}_{2} \mathrm{~S}$ & 0.89 & 0.86 & $0.66-1.02$ & $0.66-1.022$ \\
\hline $\mathrm{C}_{3} \mathrm{~A}$ & $\mathrm{Percentage} \%$ & IQS (No.5:1984) limits \\
\hline $\mathrm{C}_{4} \mathrm{AF}$ & 35 & 42.6 & ---- & ---- \\
\hline $\mathrm{C}_{3} \mathrm{~S} / \mathrm{C}_{2} \mathrm{~S}$ & 26.21 & 29.95 & ----- & ----- \\
\hline & 10.03 & 3.06 & ----- & 3.5 \\
\hline & 9.97 & 14.47 & ----- & ----- \\
\hline & 1.35 & 1.42 & ----- & ----- \\
\hline
\end{tabular}

Table 3. Properties of Fine Aggregates

\begin{tabular}{|c|c|c|c|}
\hline \multirow{2}{*}{ Properties } & \multicolumn{2}{|c|}{ Test results } & IOS No.5, [17] Limits \\
\cline { 2 - 3 } & Silica sand & River sand & \\
\hline Sulphate content $\mathrm{SO}_{3}(\%)$ & 0.45 & 0.1 & $\leq 0.5$ \\
Specific gravity & 2.42 & 2.6 & ----- \\
Water Absorption (\%) & 3.31 & 2.25 & ----- \\
\hline
\end{tabular}


Table 4. Properties of Coarse Aggregates

\begin{tabular}{|c|c|c|c|}
\hline \multirow{2}{*}{ Properties } & \multicolumn{2}{|c|}{ Test results } & \multirow{2}{*}{ OOS No.5, [17] Limits } \\
\cline { 2 - 3 } & Crushed aggregates & Rounded aggregates & \\
\hline Sulphate content $\mathrm{SO}_{3}(\%)$ & 0.08 & 0.08 & $\leq 0.1$ \\
Specific gravity & 2.68 & 2.63 & ---- \\
Absorption (\%) & 1.0 & 1.5 & --- \\
\hline
\end{tabular}

Table 5. Combined Gradation Used for RCC

\begin{tabular}{|c|c|c|c|c|c|c|c|}
\hline Sieve Size (mm) & 25.4 & 19.2 & 12.5 & 9.5 & 4.75 & 0.6 & 0.075 \\
\hline \% Finer by weight & 100 & 100 & 85 & 76.5 & 62.5 & 26.5 & 9 \\
\hline
\end{tabular}

\subsection{Coarse Aggregate}

Two types of coarse aggregate (crushed and rounded) with nominal maximum size of $19 \mathrm{~mm}$ are obtained from AL-Nibaie quarry and implemented in this work. The gravel is sieved to different sizes, oven dried, and stored. Table 4. Demonstrates the properties of coarse aggregates.

\subsection{Combined Gradation}

The required weight of each size of coarse and fine aggregates is obtained and combined to match the required gradation. The combined gradation is selected according to the limitations of dense graded concrete mixture of State Commission for Roads and Bridges SCRB, [18], Iraq. Table 5 demonstrates the combined aggregates gradation used throughout this investigation.

\subsection{Water}

Clean tap water is implemented throughout this investigation for mixing and casting of the specimens.

\subsection{Mix Design of Fresh RCC and Proportions}

The concrete mix is designed according to ASTM D-1557, [19] standard. Oven dried coarse and fine aggregates were implemented. Five different percentages of cement content are implemented (10, $12,14,16,18)$ by weight of oven dried aggregate and six different percentages of moisture content of a range of $(4-8 \%)$ with $1 \%$ increment are implemented for determination of the dry density-moisture content relationships. After mixing thoroughly by hand, the mixture was poured into cylinder mold having $100 \mathrm{~mm}$ diameter and $115 \mathrm{~mm}$ height in five successive layers. Each layer had practiced 25 blows of the modified Proctor hammer with $4.5 \mathrm{~kg}$ weight, falling from 450 $\mathrm{mm}$ height according to ASTM D-1557, [19] (modified proctor) test method. A total of 48-cylinder samples were prepared and the dry density of each specimen was determined. The moisture-density relationship was obtained for each type of mixture. Details of the mixing procedure could be found in [20].

\section{Results and Discussion}

\subsection{Influence of Portland Cement on Dry Density}

Figure 1 demonstrate the influence of silica sand (crushed) on the compaction properties of roller concrete mixtures when ordinary Portland cement was implemented. It can be observed that rounded aggregates mixture exhibits higher density when compared with crushed aggregates mixtures regardless of the cement content. This may be attributed to the fact that concrete is more workable and easier to compact when smooth and rounded aggregate are implemented instead of rough angular aggregate. Crushed aggregates produce much more angular aggregates, which have a higher surface-to-volume ratio, it has better bond characteristics while it requires more cement paste to produce a workable mixture. Similar findings were reported by [3]. However, the requirements for moisture to achieve the maximum dry density varies within $(0.5-1) \%$ for various cement content for rounded aggregates mixtures.

This could be attributed to the limited surface area of aggregates. Both mixtures require $12 \%$ of cement content for proper compaction to reach the maximum dry density. On the other hand, for crushed aggregates mixtures, the variation in the required moisture to achieve the maximum dry density is within $1 \%$. High surface area usually requires more water for lubrication process of the mixture to provide the desired workability and compaction density. Workability of the mixture is therefore influenced more by finer fraction than the coarser particles in a sample of aggregate. The maximum dry density of rounded aggregates with silica sand mixture is higher than that of crushed aggregate mixture by $(4.2,8.3,4.2,4.2$, and 5.1$) \%$ for $(18,16,14,12$, and 10) \% Portland cement content respectively. Test results agree with the work reported by [1]. 
Figure 2 demonstrates the influence of implementing river sand (rounded) on the density of RCC when ordinary Portland cement was used. It can be noted that mixtures with rounded coarse aggregates exhibit higher density as compared to mixtures with crushed coarse aggregates regardless of the cement content. This behavior could be attributed to the fact that rounded aggregates have lower surface area when compared to crushed aggregates. It can be observed that the optimum moisture content required to achieve the maximum dry density for rounded aggregates mixtures is lower than that required to achieve the same when crushed coarse aggregates are considered. More gentle shape of the density-moisture relationship could be seen on the dry side of the optimum moisture content regardless of the cement content implemented. However, higher cement content of $18 \%$ is required to achieve the maximum density for rounded aggregates mixtures while $12 \%$ cement

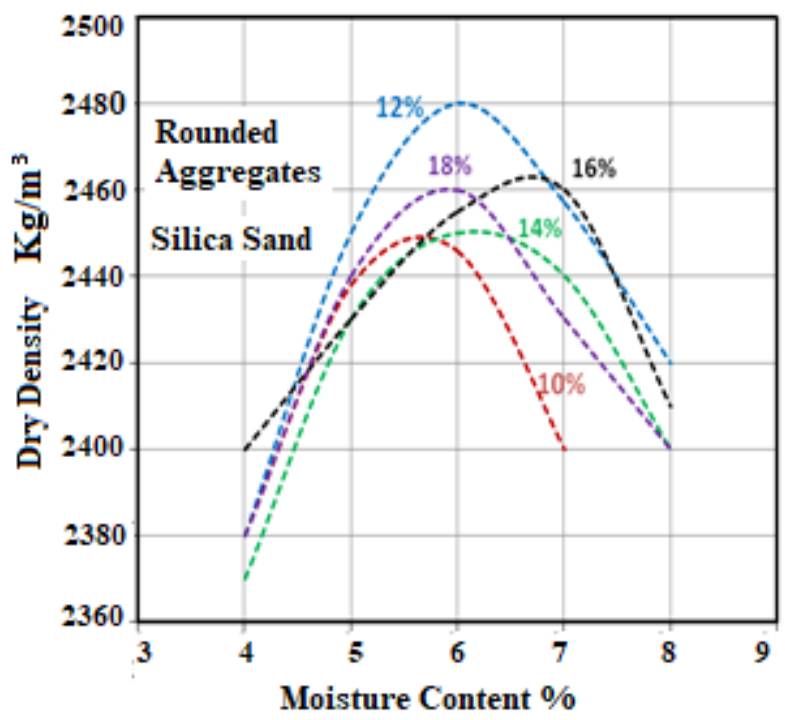

content is required to achieve the same for crushed aggregates mixtures. This may be attributed to the influence of rounded sand in changing the structure of rounded aggregates mixture and its compatibility for compaction and filling the voids. The rounded sand was able to fill the voids of the crushed coarse aggregates mixtures and reduce the surface area of the aggregate mixture. The maximum dry density of rounded aggregates with river sand mixtures is higher by (4.1, $1.4,4.1,2.0$, and 2.7$) \%$ than that of crushed aggregates mixtures for $(18,16,14,12$, and 10) \% Portland cement content respectively. Such finding agrees well with [8].

However, adoption of river sand to the rounded aggregate mixture improves the workability of concrete when compared to silica sand and the maximum dry density increases by $(1.6,0.2,1.4,0.4$, and 0.1$) \%$ for $(18,16,14,12$, and 10$)$ cement content respectively.

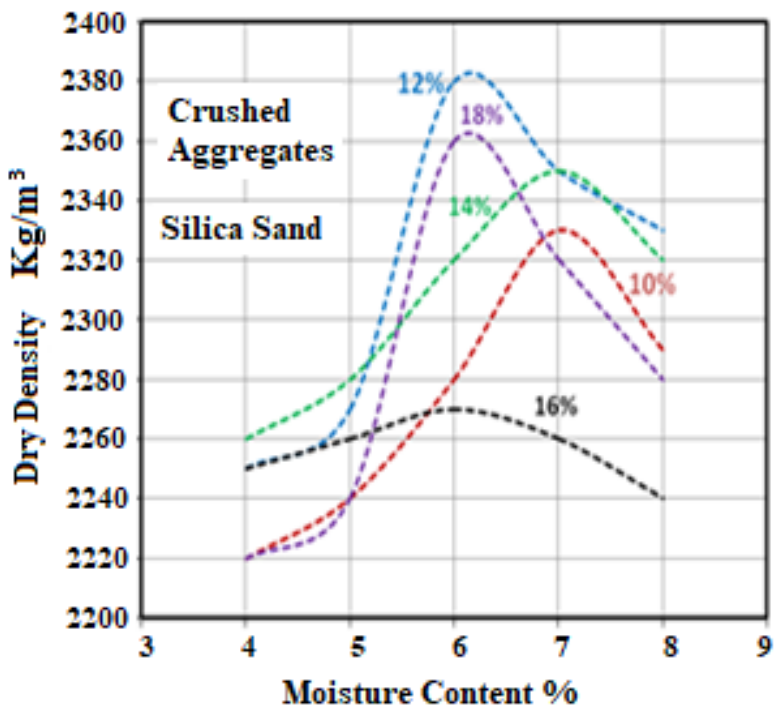

Figure 1. Influence of Silica Sand on Dry Density Using Ordinary Portland Cement
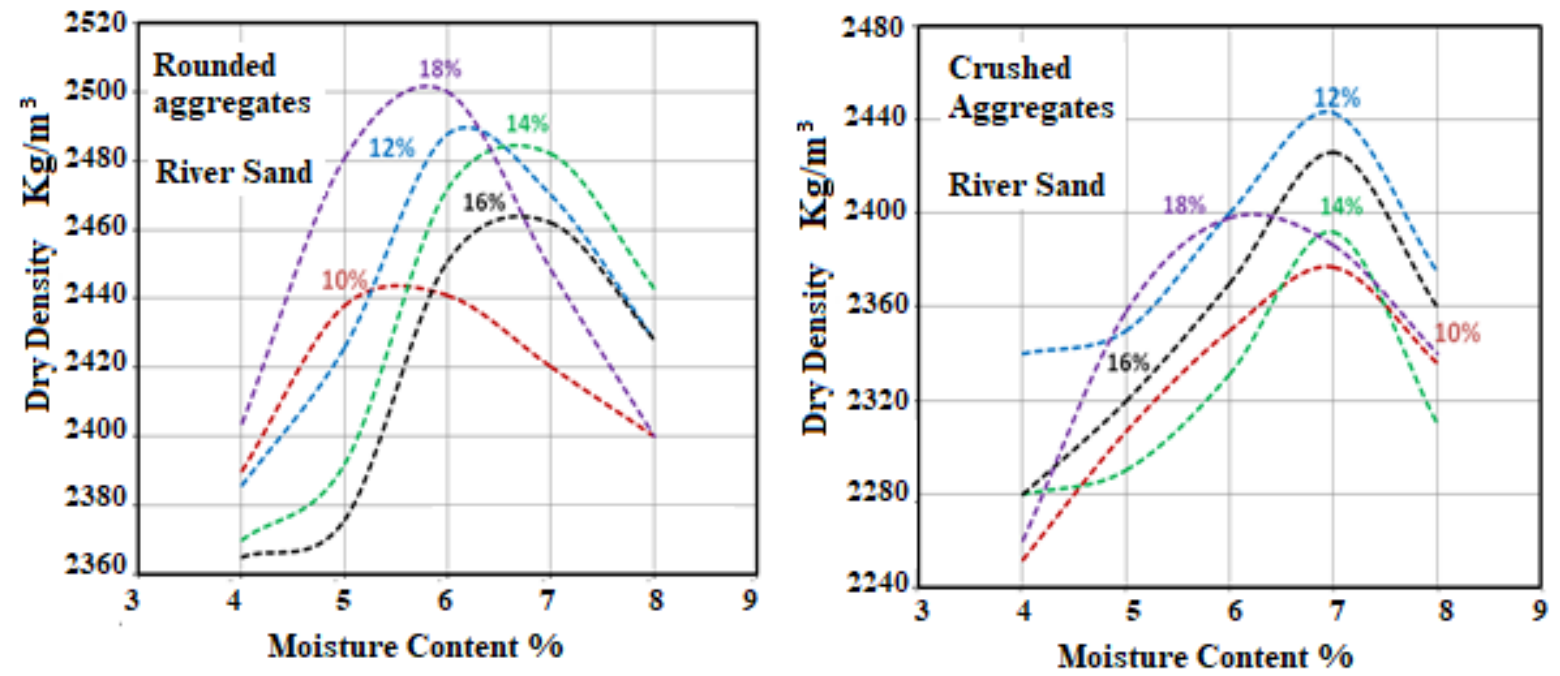

Figure 2. Influence of River Sand on Dry Density Using Ordinary Portland Cement 
On the other hand, implication of river sand into the crushed aggregates mixture improves the workability of concrete when compared to silica sand while the maximum dry density increases by $(1.7,6.6$, $1.7,2.4$, and 2.1$) \%$ for $(18,16,14,12$, and 10) \% cement content respectively. it can be detected that 12 $\%$ of Portland cement and (6 to 7) \% of moisture are proper combination when silica or river sand were implemented. [14] reported similar behavior.

\subsection{Influence of Sulphate Resistance Cement on Dry Density}

Figure 3. exhibit the influence of implementing silica sand (crushed) on the density of RCC when sulphate resistance cement was used in the mixture. It can be noted that rounded aggregates exhibit higher dry density and lower moisture content when compared to crushed aggregates. The maximum dry density of rounded aggregates with silica sand mixture is higher than that of crushed aggregate mixture by $(3.5,4,7.1$, 5.5 , and 4.4$) \%$ for $(18,16,14,12$, and 10$) \%$ sulphate resistance cement content respectively. It can be observed that for rounded coarse aggregates with silica sand, higher maximum dry density ranged between (2455 to 2520) $\mathrm{kg} / \mathrm{cm}^{3}$ could be achieved when sulphate resistance cement was implemented regardless of the cement content as compared with the range of $(2450-2480) \mathrm{kg} / \mathrm{cm}^{3}$ when Portland cement was used.

This could be attributed to the higher specific surface area of such cement of $357 \mathrm{~m}^{2} / \mathrm{Kg}$ as compared with $258 \mathrm{~m}^{2} / \mathrm{Kg}$ of Portland cement. Such fine graded cement in the fresh concrete will fill more

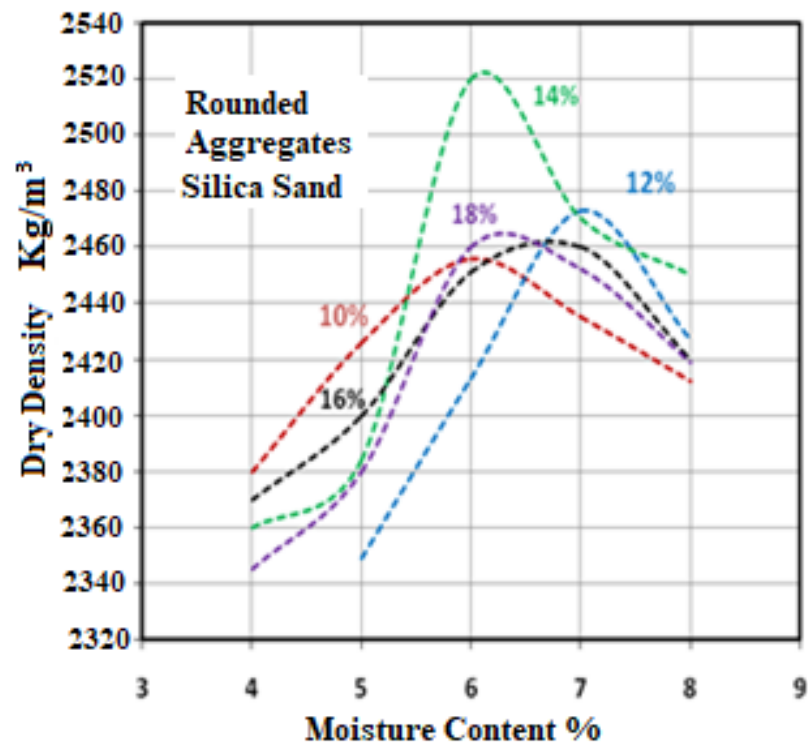

voids and increase the density. On the other hand, for crushed coarse aggregates with silica sand, higher maximum dry density ranged between (23402380) $\mathrm{kg} / \mathrm{cm}^{3}$ could be achieved when sulphate resistance cement was implemented regardless of the cement content as compared with the range of (2270 to 2380) $\mathrm{kg} / \mathrm{cm}^{3}$ when Portland cement was used. Similar findings were reported by LaHucik and Roesler, [6].

Figure 4. demonstrate the influence of river sand (rounded) on the compaction properties of concrete mixtures when implementing sulphate resistance cement. It can be noted that rounded aggregates exhibit higher dry density and lower moisture content when compared to crushed aggregates. Mohammed, [21] reported similar findings. The maximum dry density of rounded aggregates with river sand mixture is higher than that of crushed aggregate mixture by $(2.7,4.8,2.3,4.4$, and 4.2$) \%$ for $(18,16,14,12$, and 10$) \%$ sulphate resistance cement content respectively.

It can be observed that for rounded coarse aggregates with river sand, lower maximum dry density ranged between (2430 to 2465) $\mathrm{kg} / \mathrm{cm}^{3}$ could be achieved when sulphate resistance cement was implemented regardless of the cement content as compared with the range of (2440 to 2500) $\mathrm{kg} / \mathrm{cm}^{3}$ when Portland cement was used. On the other hand, for crushed coarse aggregates with river sand, lower maximum dry density ranged between (2340 to 2380) $\mathrm{kg} / \mathrm{cm}^{3}$ could be achieved when sulphate resistance cement was implemented regardless of the cement content as compared with the range of (2380 to 2445) $\mathrm{kg} / \mathrm{cm}^{3}$ when Portland cement was used.

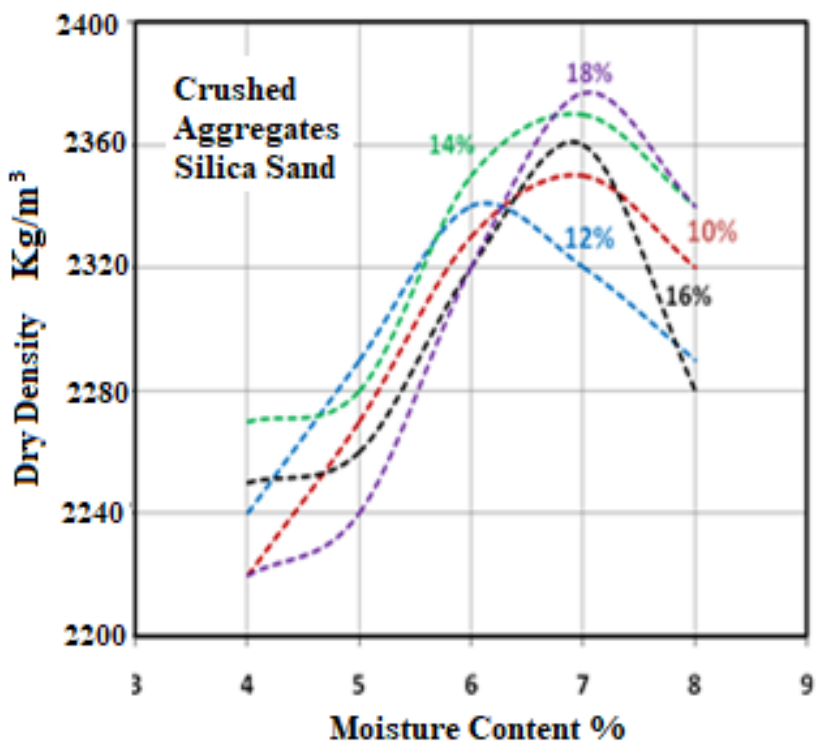

Figure 3. Influence of Silica Sand on Dry Density Using Sulphate Resistance Cement 

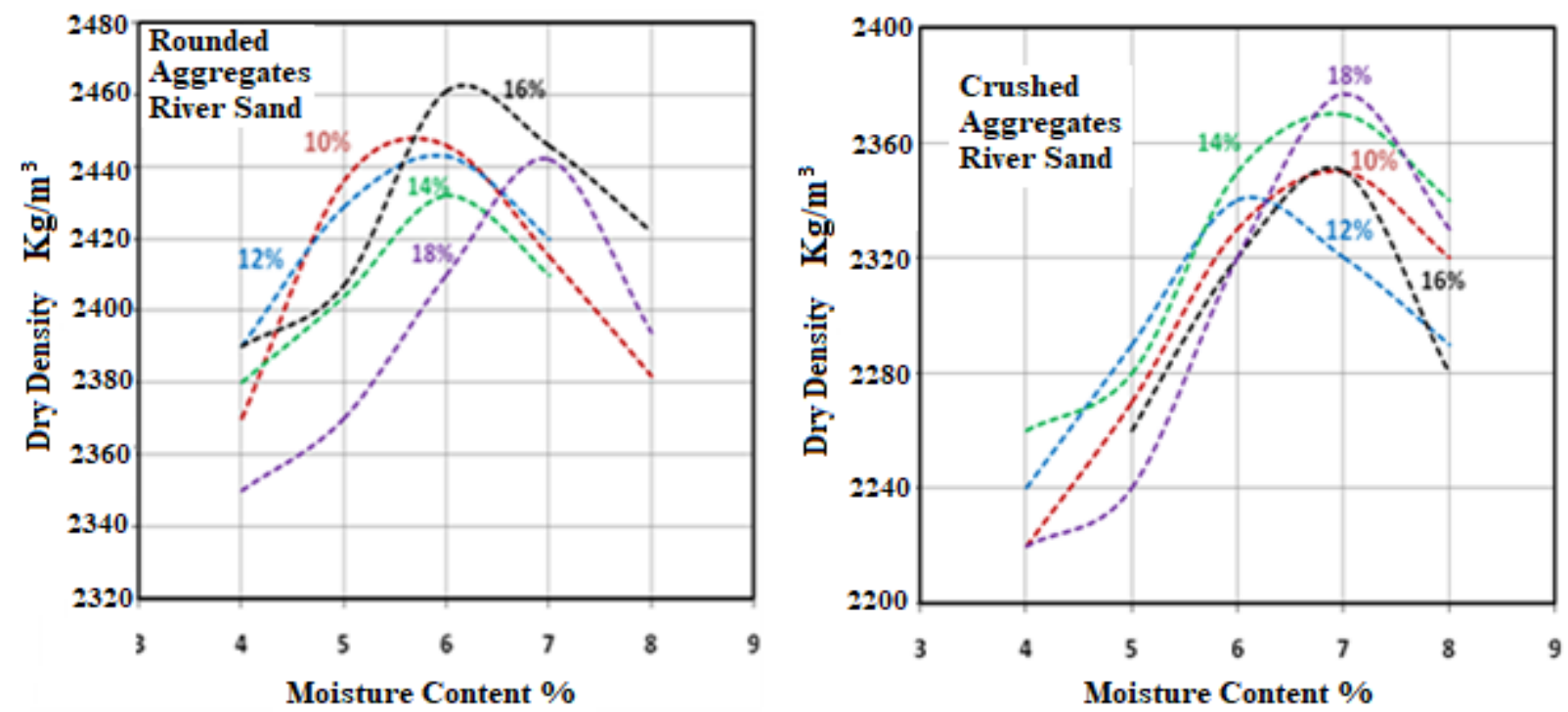

Figure 4. Influence of River Sand on Dry Density Using Sulphate Resistance Cement

This may be attributed to the excess fine particles provided by the rounded particles of river sand in addition to the finer graded cement. It can be detected that (12 and 14$) \%$ of sulphate resistance cement and (6 to 7$)$ of moisture are proper combination when silica or river sand were implemented. [22] reported similar behavior.

\section{Conclusion}

Based on the testing program and limitations of materials implemented, the following conclusions may be drawn.

1. The maximum dry density of rounded aggregates with silica sand mixture is higher than that of crushed aggregate mixture by $(4.2,8.3,4.2,4.2$, and 5.1$) \%$ for $(18,16,14,12$, and 10$) \%$ Portland cement content respectively.

2. The maximum dry density of rounded aggregates with river sand mixtures is higher by $(4.1,1.4,4.1$, 2.0 , and 2.7) \% than that of crushed aggregates mixtures for $(18,16,14,12$, and 10) \% Portland cement content respectively.

3. The maximum dry density of rounded aggregates with silica sand mixture is higher than that of crushed aggregate mixture by $(3.5,4,7.1,5.5$, and $4.4) \%$ for $(18,16,14,12$, and 10$) \%$ sulphate resistance cement content respectively.

4. The maximum dry density of rounded aggregates with river sand mixture is higher than that of crushed aggregate mixture by $(2.7,4.8,2.3,4.4$, and 4.2$) \%$ for $(18,16,14,12$, and 10$) \%$ sulphate resistance cement content respectively.
5. For rounded or crushed coarse aggregates with silica or river sand, higher maximum dry density could be achieved when sulphate resistance cement was implemented regardless of the cement content as compared with mixtures when Portland cement was used.

6. For rounded or crushed coarse aggregates with silica or river sand, lower maximum dry density could be achieved when sulphate resistance cement was implemented regardless of the cement content as compared with mixtures when Portland cement was used.

7. A combination of $12 \%$ Portland cement and (6 to 7) $\%$ of moisture is proper when silica or river sand were implemented, while (12 and 14 ) \% of sulphate resistance cement and (6 to 7) \% of moisture are proper when silica or river sand were implemented.

\section{References}

[1] C. Chhorn, Y.K. Kim, S.J. Hong, S.W. Lee, Evaluation on compactibility and workability of roller-compacted concrete for pavement, International Journal of Pavement Engineering, 20 (2019) 905-910. [DOl]

[2] M. Aghabaglou, K. Ramyar, Mechanical properties of high-volume fly ash roller compacted concrete designed by maximum density method, Construction and Building Materials, 38 (2013) 356-364. [DOl]

[3] A. Hamzah, M.B. Al-Shadeedi, Evaluation of properties of roller compacted concrete, Al- 
Nahrain Journal for Engineering Sciences, 11 (2008) 66-373.

[4] K. Kwan, J.L. Chen, adding fly ash microsphere to improve packing density, flowability and strength of cement paste, Powder Technology, 234 (2013) 19-25. [DOI]

[5] Pathania, A. Shukla, R. Vashisht, Influence of mineral additives on the packing density of ternary mix, Cement Wapno Beton, 25 (2020) 153-161. [DOI]

[6] J.R. LaHucik, J.R. Roesler, (2008) Material constituents and proportioning for rollercompacted concrete mechanical properties, Illinois Center for Transportation/Illinois Department of Transportation.

[7] S. Moradi, S. Shahnoori, Eco-friendly mix for Roller-Compacted Concrete: Effects of Persian-Gulf-Dredged marine sand on durability and resistance parameters of concrete, Construction and Building Materials, 281 (2021) 122555. [DOI]

[8] M.I. Hachani, A. Kriker, M. Seghiri, Experimental study and comparison between the use of natural and artificial coarse aggregate in concrete mixture, Energy Procedia, 119 (2017) 182-198. [DOI]

[9] K.H. Khayat, P.N.A. Libre, (2014) Roller compacted concrete: Field evaluation and mixture optimization, Center for Transportation Infrastructure and Safety/NUTC program, Missouri University of Science and Technology, 1-118.

[10] K. H. Khayat, N. A. Libre, Z. Wu, (2019) Roller Compacted Concrete for Rapid Pavement Construction. Accessed on: https://spexternal.modot.mo.gov/sites/cm/COR DT/cmr19-003 sum.pdf

[11] Chhorn, S.W. Lee, Influencing compressive strength of roller-compacted concrete, Proceedings of the Institution of Civil Engineers-Construction Materials, 171 (2016) 3-10. [DOI]

[12] Harrington, F. Abdo, W. Adaska, C.V. Hazaree, H. Ceylan, (2010) Guide for Roller-Compacted Concrete Pavements, lowa State University, 1117, USA.

[13] P. Shafigh, M. Hashemi, B. Nam, S. Koting, Optimum moisture content in roller-compacted concrete pavement, International Journal of Pavement Engineering, 21 (2020) 1769-1779. [DOI]
[14] M. Hashemi, P. Shafigh, M. Karim, C. Atis, The effect of coarse to fine aggregate ratio on the fresh and hardened properties of rollercompacted concrete pavement, Construction and Building Materials, 169 (2018) 553-566. [DOl]

[15] H. Fardin, A. Santos, Roller Compacted Concrete with Recycled Concrete Aggregate for Paving Bases, Sustainability, 12 (2020) 116. [DOl]

[16] G. Calis, S.A. Yıldızel, Investigation of roller compacted concrete: Literature review, Challenge Journal of Concrete Research Letters, 10 (2019) 63-74. [DOI]

[17] Iraqi Organization of Standards, (1984). IOS 5: 1984, for Portland cement.

[18] SCRB, State commission of roads and bridges, Standard specifications for roads and bridges. Ministry of Housing, and Construction, (2003). Iraq.

[19] ASTM D-1557, Standard Test Method for Moisture-Density Relations of Soils and SoilAggregate Mixtures Using 10lb $(4.54 \mathrm{~kg})$ Hammer and 18-in. (457-mm) Drop, Annual Book of ASTM Standards American Society for Testing and Materials. 04(8): (2002). P. 206210.

[20] S.I. Sarsam, A.S. Al Rawi, A.S. Abdul Rahim, Laboratory investigation on roller compaction technique in concrete construction, Journal of Engineering, 18 (2012) 423-432.

[21] H.A. Mohammed, (2018) Design and Evaluation of Two-Layer Roller Compacted Concrete, The University of Nottingham, UK.

[22] S.I. Sarsam, Evaluation of Roller Compacted Concrete Pavement Properties, Engineering and Development, Scientific Journal of ALMustansiria University, 6 (2002) 59-74.

\section{Funding}

No funding was received for conducting this study.

\section{Conflict of interest}

The Author has no conflicts of interest to declare that they are relevant to the content of this article.

\section{About the License}

(C) The author 2021. The text of this article is open access and licensed under a Creative Commons Attribution 4.0 International License 


\section{Cite this Article}

Saad I. Sarsam, Assessing the Influence of Aggregates and Cement Types on Fresh Roller Compacted Concrete Mixture, International Research Journal of Multidisciplinary Technovation, Vol 3, Iss 3 (2021) 23-31.

DOI: https://doi.org/10.34256/irimt2134 